\title{
Structure for Categorization of EcoDesign Methods and Tools
}

\author{
Mattias Lindahl and Sara Ekermann
}

\section{Linköping University Post Print}

\section{Tweet}

N.B.: When citing this work, cite the original article.

Original Publication:

Mattias Lindahl and Sara Ekermann, Structure for Categorization of EcoDesign Methods and Tools, 2013, Re-engineering Manufacturing for Sustainability: Proceedings of the 20th CIRP International Conference on Life Cycle Engineering, Singapore 17-19 April, 2013, 117-122. http://dx.doi.org/10.1007/978-981-4451-48-2_19

Copyright 2013: Springer Science + Business Media Singapore http://www.springer.com/

Postprint available at: Linköping University Electronic Press http://urn.kb.se/resolve?urn=urn:nbn:se:liu:diva-102472 


\title{
Structure for Categorization of EcoDesign Methods and Tools
}

\author{
Mattias Lindahl and Sara Ekermann \\ Department of Management and Engineering, Linköping University, Linköping \\ Sweden
}

\begin{abstract}
EcoDesign methods and tools play an important role in assuring that environmental aspects are considered in the product development process. However, despite the large number of EcoDesign methods and tools in the literature, they are rarely implemented and used in product development. The objective of this paper is present a structure for how to categorize different EcoDesign methods and tools, or more specifically, a structure that can work as guidance for, depending on the context and need, selecting EcoDesign methods and tools. Based on a literature review, a structure for categorization of EcoDesign methods and tools is presented, and a total of 28 EcoDesign methods and tools are mapped. These EcoDesign methods and tools include benchmarking tools, tools for investigating customer needs, concept generation and elimination tools and evaluating and assessment tools.
\end{abstract}

Keywords: Design for Environment (DfE), Product Development, Evaluation, Engineering Designer

\section{INTRODUCTION}

Engineering designers can do much for the environment by considering the environmental aspects of the products they are developing. By considering the product's entire life cycle in the early phases of product development, money can be saved, as well as the environment.

EcoDesign is not a specific method or tool, but rather a way of better design through analyzing and synthesizing in order to reduce environmental impacts throughout the product's entire life cycle. In short, do more with less - and be more resourceeffective and efficient.

Most of a product's total life cycle cost is determined early in the design process, and this is related to economic as well as environmental concerns [1]. Decisions made in the early phases are therefore very important, and it is beneficial to use proven methods and tools to assure that the result is the best possible.

EcoDesign methods and tools play an important role in assuring that the environmental aspects are considered in the product development process. However, despite the large number of EcoDesign methods and tools in the literature (see e.g. [2, 3]), they are rarely implemented and used in product development [4]. Could it be that they have been designed mainly with environmental issues in focus, neglecting the potential users' requirements on methods and tools?

Lindahl concludes that an EcoDesign method/tool as well as a common method or tool must exhibit the following [4]:

(1) be easy to adopt and implement - whether a method or tool fulfills the three following requirements is of lesser importance if it is due to a problem with adoption and implementation and becomes seen as having a low degree of usability, and therefore is not utilized by the designers in their daily work. This requirement is the key for a method or tool to become actively used.

(2) facilitate designers to fulfill specified requirements on the presumptive product and at the same time
(3) reduce the risk that important elements in the product development phase are forgotten.

Both of these two latter requirements relate to a method or tool's degree of appropriateness. The second and third requirements are related to the fourth requirement, which is considered by the author to be the most important, that the use of the method or tool:

(4) must reduce the total calendar time (from start to end) to solve the task. If the method or tool helps designers to fulfill specified requirements, it will also most likely help them to reduce the calendar time as well as the number of working hours needed to accomplish the product development. This is also something that enables designers to introduce changes in early phases of the product development when changes still are easy to make. Likewise, if the method or tool reduces the risk that important moments in the product development are forgotten, it will most likely have a positive effect and reduce the calendar time and number of working hours needed.

\section{OBJECTIVE}

Based on the above, this paper's objective is to present potential criteria that can be used for selecting EcoDesign methods and tools: criteria that can also be used when developing new or modifying existing ones. The objective is also to present a structure for how different EcoDesign methods and tools can be categorized. This structure can work as a guidance for, depending on the context and need, selecting EcoDesign methods and tools.

\section{METHOD}

A literature review was conducted in order to identify potential criteria on methods and tools for product development, with special focus on EcoDesign methods and tools. The literature study is based on the keywords criteria, requirements, utilization, and usability, together with methods or tools and product development. The results are compared and evaluated in order to answer the question of what criteria could be used. 
In order to develop and evaluate a structure for how different EcoDesign methods and tools can be categorized, a literature review was done to identify a number of EcoDesign methods. The article databases accessible through Linköping University's library were used (e.g. Scopus and Academic Search Primer) in combination with the university library for research on published books on the subject. The encountered results were crosschecked on Google in order to investigate if they are easy to access and find on the Internet. Keywords used were e.g.: Design for Environment, DFE, EcoDesign, Sustainable Design, Environmentally Conscious Design, and "Miljöanpassad Produktutveckling" (keyword in Swedish for "Environmentally Adopted Product Development").

References in books and articles describing and listing many different methods were tracked one step, and the original sources were listed as references as extensively as possible. When the original source was not available at the university library or on the Internet, the reference to the method was given "original source" according to "source where it is found". Different sources describing approximately the same methods that could be considered close variants to the same method were linked together as one method, but referred to several sources.

\section{THEORETICAL FRAMEWORK}

\subsection{Product Development Models}

In order to make their product development more efficient and effective, companies use various forms of product development models. These are, especially at small companies, more or less formalized and documented. According to ENDREA [5], product development is defined as: "all activities in a company aiming at bringing a new product to the market. It normally involves design, marketing and manufacturing functions in the company".

The rate of market and technological changes has accelerated in the past decade. This implies that companies must be pro-active in the sense that they must be able to rapidly respond to fluctuations in demand [6]. Central to competitive success in the present highlyturbulent environment is the company's capability to develop new products [7]; to improve, further develop and optimize old products; and to do so faster than competitors [8]. Designers must develop and proceed faster, while at the same time covering an increased number of different demands on the product.

When developing new products, designers typically follow a general procedure, a so-called product development model. A product development model is a process description of the sequence of activities in a company aiming at bringing a new product to market. It normally involves design, marketing and manufacturing activities. An extensive number of prescriptive models for performing product development have been developed to make product development more effective and efficient; some examples are provided by Ulrich and Eppinger [9], Andreasen and Hein [10], Olesen [11] and Roozenburg and Eekels [12].

These product development models often divide the product development into several phases. For example, Ulrich and Eppinger [9] divide it into six phases: Planning, Concept Development, System-Level Design, Detail Design, Testing and Refinement, and Production Ramp-Up, as shown in Figure 1. The process is described as linear, but is actually iterative.

The product development process could have different focuses depending on the objectives of the projects. There are many considerations that the designer needs to implement simultaneously and that might need to be in focus for the success of the product; examples include optimizing the manufacturing process, assembly customer satisfaction or environmental aspects $[13,14]$.

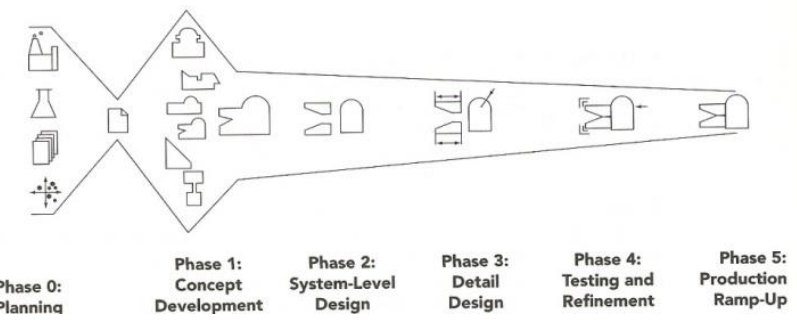

Figure 1: Ulrich and Eppinger's Product Development Model [9].

\subsection{Product Development Methods and Tools}

Methods and tools are important in product development, as they help in structuring the work, aid in communication and contribute with integrated knowledge and experience [4]. There are methods and tools for almost everything that is encountered in the product development process, ranging from creativity tools to structuring tools to evaluation and decision tools. A company's product development model often describes which methods and tools are used, and when and why they are used during the product development process. Thus, the existence of a product development model may give some indication of the formal use of methods and tools among designers.

\subsection{EcoDesign}

Environmental considerations in product development could be beneficial in several ways; minimization of resource usage, optimization manufacturing processes and reuse of materials and products are efforts that benefit the environment as well as the economy of the company.

EcoDesign is an approach to product development that focuses on minimizing the environmental impact of all the product's life cycle stages. EcoDesign is a word commonly used to describe this approach, while other words meaning slightly the same thing are also used; for example, environmentally conscious design, Design for Environment (DfE) and green design are other commonly-used expressions meaning the same thing [15]. A broader approach is sustainable design, that along with the environmental sustainability also considers the social and economic aspects [16].

The life cycle perspective, which is central when performing EcoDesign, considers the entire life cycle of a product, from cradle to grave. To improve the environmental aspects of a product, not only one part of the product life cycle could be studied; such an approach could result in an improvement in that part of the life cycle, but a worse overall environmental impact. The life cycle phases of an ordinary product could be e.g. material extraction, manufacturing, use, and end-of-life (EOL) treatment [17].

It is important that the EcoDesign process is built into the existing product development model in order to achieve the environmental goals that are set in the organization [18]. The EcoDesign process should therefore be constructed by carefully studying the current product development model [18].

\subsection{EcoDesign Methods and Tools}

Many methods and tools exist to facilitate an EcoDesign approach in product development. Methods and tools available for EcoDesign purposes range from simple checklists and guideline tools, to supporting software tools, to material selection tools, to complex life cycle assessment tools [3].

The EcoDesign method or tool in this paper refers to any specific procedure with a specified desired outcome that could be performed in a product development process in order to support the work towards an environmental goal. 


\section{POTENTIAL CRITERIA FOR SELECTING ECODESIGN METHODS AND TOOLS}

Methods and tools that could be used in the early design phases have greater potential to affect the environmental impacts of the product $[4,18]$.This is also referred to as the design paradox, and could be applied in environmental life cycle aspects as well as the costs of the project that usually are considered.

According to Ryding [16], useful methods and tools must meet certain criteria. For example, the methods and tools must be: easy to use and review; standardized so that results can be compared; universal, flexible and fast; and enable sensitivity analyses. Further, the use of the methods and tools needs to give easily interpreted and comparable results as well as provide basic data for environmental product declarations and long-term environmental planning [16]. The criteria are presented in a textbook for industry, and describe the requirements for methods and tools in order to correctly accommodate the demands of industry in determining the environmental impact of the products.

As described in the introduction of this paper, Lindahl [4] has concluded that there are four basic requirements on methods and tools for them to be useful. Those are that the method or tool must be "be easy to adopt and implement", "facilitate designers to fulfill specified requirements", "reduce the risk that important elements in the product development phase are forgotten" and most important "reduce the total calendar time (from start to end) to solve the task". Based on an interview study at an international Swedish industrial equipment company, the same author [19] concludes that important criteria are: the method/tool must be valuable for the purpose; the customer requires that the method is used; it covers relevant and common problems; and it is not experienced as too complex or complicated to use.

According to Lofthouse, industrial designers have special demands on EcoDesign methods and tools [20]; she divides designers' requirements for useful EcoDesign tools into five categories: service, content, time, style and culture. The study is based on four surveys, a pilot study and semi-structured interviews with industrial designers at different competence levels and at different sizes of companies. The study showed that designers often were either overwhelmed by the information given in the methods, or that the tools were too general and hard to use. They also had the belief that the tools did not focus on design, but only on analysis of existing products, and that in general they were too time consuming. The designers asked for quick and easy guidance together with information and education that could support their learning. Another requirement was the use of examples and images to illustrate results, because that fits better into how designers work. They were often requesting more specific information, and methods that could be used by individuals. The designers often did not understand or read complicated technical explanations; they would rather appreciate less technical approaches with visual communication and minimal text, presented in an understandable language [20].

Handfield et al. [21] describe the problems with incorporating EcoDesign in product development; according to these authors, the problems identified are strongly correlated to requirements that could be set for the methods and tools to fulfill. The study was based on interviews with managers and engineers in ten companies, and focused on implementation of environmentally conscious manufacturing in the product development process. The study found that design engineers often were negative to the implementation of environmental concerns, for the reasons that the results are often hard to prove, they did not think that it was included in the primary job, and it is often hard to motivate tradeoffs towards ordinary technical requirements. They also believed that the environmental aspects would have negative impacts on costs, lead time and quality. In addition, they were not comfortable with the tools that were available, as they required education and were too time consuming [21]. The authors of this paper interpret the problems encountered in the study [21] as the methods and tools available not being sufficiently satisfying. In order to satisfy the design engineers the methods and tools used for EcoDesign must be easy to use, reduce the time of work, require short or no setuptime or education, be incorporated in daily work, support trade-off decisions and have a clearly visible result and purpose.

The requirements found in the literature study are summarized in Table 1. The most frequent requirements were narrowed down to the following four categories: Expected Result (could give information on: whether the method is inspiring, if the result is measurable, a foundation for decision-making, comparable results, if there is interpretable data, and the method's reliability). Product Development Process Phase, Considered Life Cycle Stages (and life cycle perspective, yes/no), Time and Difficulty (complexity, accessibility and expertise knowledge needed).

Table 1: Identified criteria for EcoDesign methods and tools.

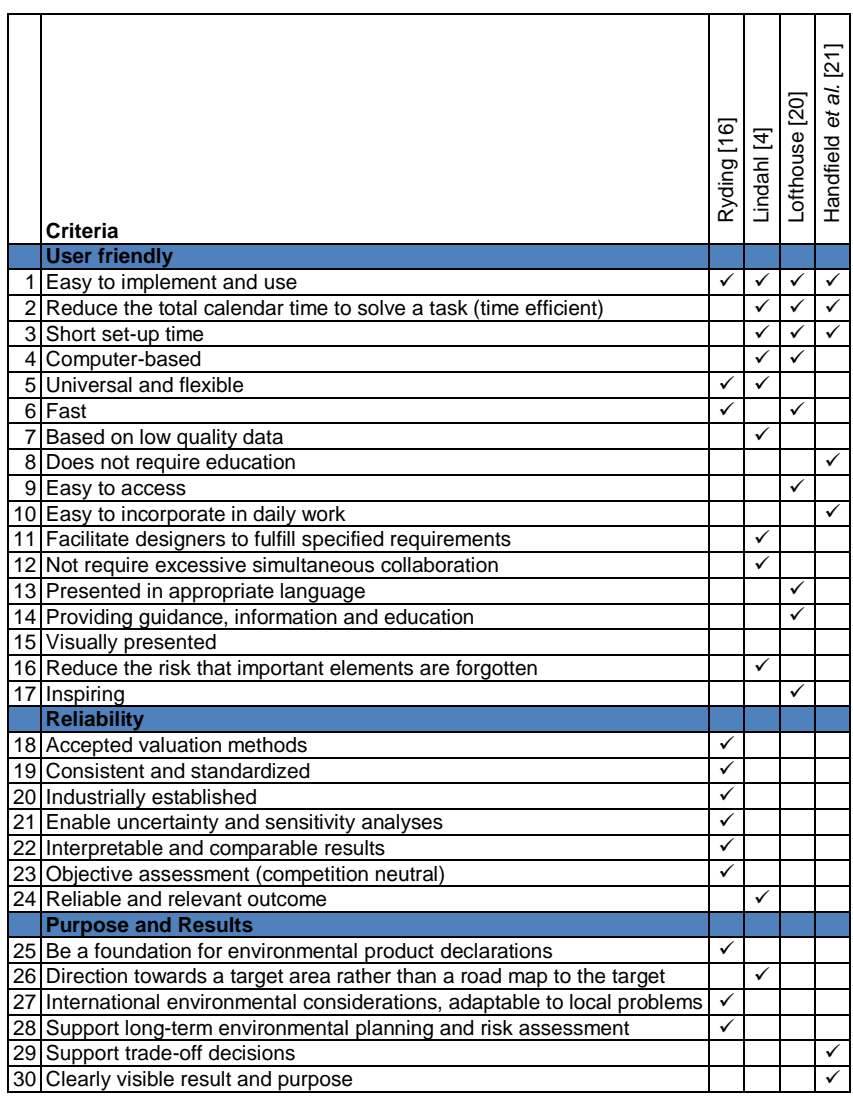

\section{ECODESIGN METHODS AND TOOLS}

This section lists some of the EcoDesign methods and tools found in the literature review. Identified methods and tools can be divided into different types aimed at e.g. Investigating Customer Environmental Needs, Benchmarking, Idea and Concept Generation and Concept Eliminations.

In order to bring structure, identified EcoDesign methods and tools were categorized according to Table 2, which is based on the criteria found in Section 5 . 
Table 2: Template for describing EcoDesign methods and tools.

\begin{tabular}{|l|l|}
\hline $\begin{array}{l}\text { Phase of } \\
\text { development } \\
\text { process }\end{array}$ & $\begin{array}{l}\text { Planning/ Concept Development/ System-Level } \\
\text { Design/ Detail Design/ Testing and Refinement/ } \\
\text { Production Ramp-Up }\end{array}$ \\
\hline $\begin{array}{l}\text { Expected } \\
\text { results }\end{array}$ & $\begin{array}{l}\text { Describes what outcome the user could expect when } \\
\text { using the tool }\end{array}$ \\
\hline Time & Fast/Somewhat time consuming/Time consuming \\
\hline Difficulty & Very Easy/Easy/Medium/Hard \\
\hline $\begin{array}{l}\text { Life Cycle } \\
\text { Perspective }\end{array}$ & $\begin{array}{l}\text { Yes/No / Resource extraction/Product } \\
\text { Manufacturing / Product Use/ End-of-Life (EOL) }\end{array}$ \\
\hline Sources & $\begin{array}{l}\text { References where methodology and more } \\
\text { information can be found }\end{array}$ \\
\hline
\end{tabular}

In Table 3, some of the identified EcoDesign methods and tools are presented. Symbols, which are explained below, are used to make the table easier to read. The table summarizes the methods and tools in alphabetical order and indicates the phase of the product development process, life cycle perspective, time, difficulty, and accessibility on the Internet.

\section{Symbol explanations:}

\section{Phase of product development process:}

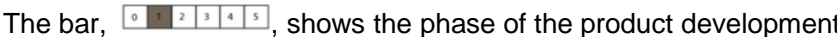
process where the method is useful. The reference is Ulrich and Eppinger's Product Development Model [9].

Life cycle perspective:

$\checkmark \quad$ The method or tool has a life cycle perspective.

$x \quad$ The method or tool has no life cycle perspective.

$\checkmark / x$ The method or tool has no built-in life cycle perspective, but the product developers can implement a life cycle perspective if they like.

Time:

The time has been estimated from information in the literature and comparisons on the work burden between the different methods. Many methods could be performed with different scopes; therefore, the amount of time that would be needed to complete a useful and reliable result has been approximated.

- Not time consuming - less than 1 person-days.

- Somewhat time consuming - 1-5 person-days.

Time consuming - more than 5 person-days.

\section{Difficulty:}

The difficulty has been evaluated by the authors, with help from information found in the literature. Some method descriptions mention that environmental specialists are needed, and that the classification is therefore a difficulty level of "medium". The methods marked "very easy" were understood by the author without reading the descriptions and methodology, while the ones marked "easy" were understood and possible to perform by the author with help from the provided manual or step-by-step descriptions. The methods marked "hard" require expert knowledge in both how to perform the method and environmental concerns.

त्ता Very easy - Could be performed intuitively.

Easy - Can be performed with help from a manual.

-1 Medium - Needs some education on method or extensive knowledge in environmental concerns.

Hard - Requires expert knowledge.

\section{Accessible on the Internet:}

$\begin{array}{ll}\checkmark & \text { Yes } \\ x & \text { No } \\ & \text { Not free - license or costly }\end{array}$

Table 3: Summary of EcoDesign methods and tools.

\begin{tabular}{|c|c|c|c|c|c|}
\hline Method & 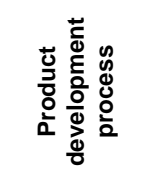 & 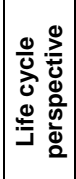 & $\stackrel{\oplus}{\underline{E}}$ & 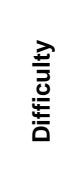 & 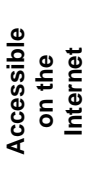 \\
\hline Cumulative energy demand [22] & $0.11+1.15$ & & 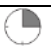 & & $\checkmark$ \\
\hline $\begin{array}{l}\text { Checklist for environmentally } \\
\text { conscious electronics [23] }\end{array}$ & 0 . & $\checkmark$ & & & $\checkmark$ \\
\hline Contingent valuation [24] & \begin{tabular}{|l|l|l|l|l|l|}
0 & \\
\end{tabular} & $x$ & & & $\checkmark$ \\
\hline \begin{tabular}{|l|} 
Cleaner Technologies \\
Substitutes Assessment [25]
\end{tabular} & $0.12^{2} \cdot 3 / 4 \mid 5$ & $\checkmark$ & & & $\checkmark$ \\
\hline $\begin{array}{l}\text { Design for Environmental } \\
\text { Compliance Workbench Tool } \\
\text { [26] }\end{array}$ & \begin{tabular}{l|l|l|l|l|l|}
0 & 1 & 2 \\
\end{tabular} & $\checkmark$ & & & $x$ \\
\hline Disassembly analysis [23] & \begin{tabular}{|l|l|l|l|l|}
0 & 1 & 2 & 3 & 4 \\
\end{tabular} & $x$ & 2 & & $\checkmark$ \\
\hline Dominance Matrix [22] & \begin{tabular}{|l|l|l|l|l|}
5 & 0 \\
\end{tabular} & $x$ & ( ) & & $x$ \\
\hline Eco Strategy wheel [23] & \begin{tabular}{|l|l|l|l|l|l|}
0 & $V^{2}$ & 3 & 4 & 5 \\
\end{tabular} & $\checkmark$ & 6 & & $\checkmark$ \\
\hline Eco Compass [22] & \begin{tabular}{|l|l|l|l|l|}
0 \\
\end{tabular} & $\checkmark$ & 5 & & $\checkmark$ \\
\hline EcoDesign PILOT [27] & $0+\left.\right|^{2}|3|+\mid 5$ & $\checkmark$ & & & $\checkmark$ \\
\hline EcoPaS [28] & \begin{tabular}{|l|l|l|l|l|}
0 & \\
\end{tabular} & $x$ & & & $\checkmark$ \\
\hline $\begin{array}{l}\text { Environmental Effect Analysis } \\
\text { (EEA) [29] }\end{array}$ & $0.12+3|+| 5$ & $\checkmark$ & & & $\checkmark$ \\
\hline $\begin{array}{l}\text { Environmental Objectives } \\
\text { Deployment [30] }\end{array}$ & 01 & $\checkmark / x$ & & & $x$ \\
\hline $\begin{array}{l}\text { Environmental Benchmarking } \\
\text { (EPAss) [31] }\end{array}$ & 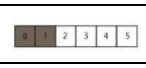 & $v / x$ & & & $\checkmark$ \\
\hline $\begin{array}{l}\text { The Environmentally } \\
\text { Responsible Product } \\
\text { Assessment Matrix [32] } \\
\end{array}$ & $0 .\left.\right|^{2}+3 / 45$ & $\checkmark$ & & & $\checkmark$ \\
\hline Function analysis [23] & \begin{tabular}{|l|l|l|l|l|}
0 \\
\end{tabular} & $\checkmark / x$ & & & $\checkmark$ \\
\hline $\begin{array}{l}\text { House of Environmental Quality } \\
\text { [32] }\end{array}$ & 415 & $\checkmark$ & & & $x$ \\
\hline IdeMat [33] & \begin{tabular}{|l|l|l|l|l|}
0 & \\
\end{tabular} & $\checkmark$ & & & $\checkmark$ \\
\hline $\begin{array}{l}\text { Life Cycle Assessment (LCA) } \\
\text { [34] }\end{array}$ & 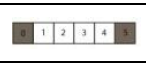 & $\checkmark$ & & & $\checkmark / 9$ \\
\hline $\begin{array}{l}\text { Life-Cycle Design Strategies } \\
\text { (LiDS) Wheel [35] }\end{array}$ & 아 & $\checkmark$ & & & $\checkmark$ \\
\hline $\begin{array}{l}\text { Materials-Energy-Chemicals- } \\
\text { Other (MECO) Matrix [36] }\end{array}$ & 01 & $\checkmark$ & & & $\checkmark$ \\
\hline $\begin{array}{l}\text { Material, Energy Consumption } \\
\text { and Toxic discharge (MET) } \\
\text { matrix [23] }\end{array}$ & 0.1213 .45 & $\checkmark$ & & & $\checkmark$ \\
\hline $\begin{array}{l}\text { Material Input Per Service unit } \\
\text { (MIPS) [22] }\end{array}$ & 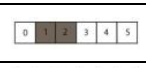 & $x$ & & & $\checkmark$ \\
\hline Product Ideas Tree (PIT) [37] & \begin{tabular}{|l|l|l|l|l|l|}
0 & \\
\end{tabular} & $\checkmark$ & & & $\checkmark$ \\
\hline $\begin{array}{l}\text { Quality Function Deployment for } \\
\text { Environment (QFDE) [38] }\end{array}$ & $\left.\left.0.1\right|^{2}\left|3^{3}\right|\right|^{5}$ & $\checkmark$ & & & $\checkmark$ \\
\hline Ten Golden Rules [39] & $0.12|14| 5$ & $x$ & 9 & 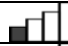 & $\checkmark$ \\
\hline TRIZ used in EcoDesign [40] & \begin{tabular}{|l|l|l|l|l|}
0 & 1 & 2 & 3 & 4 \\
\end{tabular} & $\checkmark / x$ & & & $\checkmark$ \\
\hline $\begin{array}{l}\text { EDIP (Environmental Design of } \\
\text { Industrial Products) [36] }\end{array}$ & 012 & $\checkmark$ & & & 7 \\
\hline
\end{tabular}

\section{DISCUSSION AND CONCLUSIONS}

\subsection{Criteria on EcoDesign Methods and Tools}

The objective was to present potential criteria that can be used for selecting EcoDesign methods and tools, and this has been done through the literature study of criteria for choosing EcoDesign methods and tools. Only a few studies have been made in this field, and they showed quite different results; one reason could be that the studies have had different approaches and interpretations on what is important when utilizing methods and tools. For example, Lindahl [4] focused on the requirement the engineering designers have for using methods and tools, and he does not consider if the results of the method are appropriate from an environmental perspective. Ryding [16], on the other hand, specifies criteria that the methods should fulfill in order to produce appropriate results 
from an environmental perspective. Lofthouse [20] analyzes the industrial designers' special demands on EcoDesign methods and tools that are quite different since their technical knowledge in general is much lower than that of engineering designers. It seems like most EcoDesign methods and tools are developed for the use of engineers and few tools exist for industrial designers. However, those criteria described by Lofthouse could be important to consider whenever industrial designers are participating in the EcoDesign work.

Many different criteria could be used for selecting EcoDesign methods and tools. The most common criteria mentioned in the literature and in the interview study are that the methods must be useful, provide help for the user to reach the goal, and have a clearly defined purpose and measurable results. Also, it is important that the tools not are too complex and time consuming compared to the benefit.

\subsection{EcoDesign Methods and Tools}

A second objective was to present a structure for how different EcoDesign methods and tools can be categorized - a structure that can work as guidance for, depending on the context and need, selecting EcoDesign methods and tools.

In order to do that, 28 EcoDesign methods and tools were identified through a literature review and later used to test the proposed categorization structure. They included benchmarking tools, tools for investigating customer needs, concept generation and elimination tools, evaluating and assessment tools, as well as checklist and guideline tools.

It should be noted that the aim of gathering the methods and tools is not to claim that this paper covers all existing EcoDesign methods and tools. Instead, the purpose is to provide an illustration on how environmental methods and tools could be categorized in order to support selection of suitable ones depending on the actual context. Nevertheless, an interesting note is that many of the identified EcoDesign methods and tools are derived from methods and tools used in other purposes in product development, for example the functional analysis and the morphological box that is redesigned to incorporate environmental requirements as well. Other EcoDesign methods derived from other product development methods and tools are for example Environmental Effect Analysis (EEA) and Quality Function Deployment for Environment (QFDE). Those methods and tools could be easy to learn and implement if the user is already familiar with the original method.

\subsection{Structure for Categorization of EcoDesign Methods and Tools}

The second objective was to present a structure for how different EcoDesign methods and tools can be categorized, and this is done in the previous section. This structure is tested by using the identified EcoDesign methods. The conclusion is that this structure can be used as guidance for companies, engineers, etc. when selecting suitable EcoDesign methods and tools. It can be used both as a way to structure EcoDesign methods and tools, as well as used as categories when trying to describe the actual context in which the EcoDeign method or tool is supposed to be used.

\section{REFERENCES}

[1] Billatos, S.B. and Basaly, N.A., Green Technology and Design for the Environment, 1997: Taylor \& Francis Inc.

[2] Simon, M., Evans, S., McAloone, T.C., Sweatman, A., Bhamra, T., and Poole, S., Ecodesign Navigator - A Key resource in the Drive towards Environmentally Efficient Product Design, 1998, Manchester, UK: Manchester Metropolitan University, Cranfield University \& EPSRC.
[3] Mizuki, C., Sandborn, P.A., and Pitts, G., Design for environment-a survey of current practices and tools. Electronics and the Environment, 1996. ISEE-1996., Proceedings of the 1996 IEEE International Symposium on, 1996: p. 1-6.

[4] Lindahl, M., Engineering Designers' Requirements on Design for Environment Methods and Tools, in Industrial Engineering and Management, 2005, KTH: Stockholm, Sweden.

[5] ENDREA, ENDREA nomenclature, ENDREA - Engineering Research and Education Agenda, 2001: Linköping, Sweden.

[6] Collaine, A., Lutz, P., and Lesage, J.-J., A method for assessing the impact of product development on the company. International Journal of Production Research, Taylor \& Francis, 2002. 40(14): p. 3311 - 3336.

[7] Gonzalez, F.J.M. and Palacios, T.M.B., The effect of new product development techniques on new product success in Spanish firms. Industrial Marketing Management, 2002. 31(3): p. 261-271.

[8] Stalk, G.J. and Hout, T.M., Competing Against Time - How Time-Based Competition is Reshaping the Global Markets, 1990, New York, USA: The Free Press, A Division of Macmillan Inc. 285.

[9] Ulrich, K.T. and Eppinger, S.D., Product Design and Development, 2000, New York: McGraw-Hill Higher Education.

[10] Andreasen, M.M. and Hein, L., Integrated Product Development, 1987, Bedford, UK: IFS Publications Ltd.

[11] Olesen, J., Concurrent Development in Manufacturing - based on dispositional mechanisms, in Institute for Engineering Design, 1992, Technical University of Denmark: Lyngby, Denmark. p. 154.

[12] Roozenburg, N.F.M. and Eekels, J., Product Design: Fundamentals and Methods, 1995, West Sussex, UK: John Wiley \& Sons, Ltd.

[13] Graedel, T.E. and Allenby, B.R., Design for Environment, 1998, Upper Saddle River, New Jersey: Prentice Hall.

[14] Luttropp, C., Design for Disassembly, in Department of Machine Design, 1997, Royal Institute of Technology: Stockholm, Sweden.

[15] van Hemel, C.G., EcoDesign Empirically Explored - Design for Environment in Dutch Small and Medium Sized Enterprises, 1998, Delft University of Technology: Delft, Netherlands.

[16] Ryding, S.-O., et al., Miljöanpassad produktutveckling (in Swedish), 1995, Stockholm, Sweden: Industrilitteratur AB.

[17] Rydh, C.J., Lindahl, M., and Tingström, J., Livscykelanalys en metod för miljöbedömning av produkter och tjänster (Life Cycle Assessment - a method for environmental assessment of products and services). 1st ed 2003, Lund, Sweden: Studentlitteratur AB. 228.

[18] Kutz, M., ed. Environmentally conscious Mechanical Design. 2007, John Wiley \& Sons, Inc: New Jersey.

[19] Lindahl, M., Engineering designers' experience of design for environment methods and tools - Requirement definitions from an interview study. Journal of Cleaner Production, Elsevier, 2006. 14(5): p. 487-496.

[20] Lofthouse, V., Ecodesign tools for designers: defining the requirements. Journal of Cleaner Production, 2006. 14(15): p. 1386-1395.

[21] Handfield, R.B., Melnyk, S.A., Calantone, R.J., Curkovic, S., Integrating environmental concerns into the design process: the gap between theory and practice. Engineering Management, IEEE Transactions on, 2001. 48(2): p. 189-208.

[22] Charter, M. and Tischner, U., eds. Sustainable Solutions Developing products and services for the future. 2001, Greenleaf Publishing Limited: Sheffield, UK. 
[23] Norrblom, H.L., Jönbrink, A.K., and Dahlström, H., EcoDesign - Praktisk vägledning, 2000, Göteborg, Sweden: Institutet för Verkstadsteknisk Forskning.

[24] Thurston, D., L. and Hoffman, I.W., F. Integrating Customer Preferences into Green Design and Manufacturing. in Proceedings of the 1999 IEEE International Symposium on Electronics and the Environment. 1999. Danver, Massachusetts.

[25] Kincaid, L., Davis, E., Allen, G., and Jed, M., Cleaner Technologies Substitutes Assessment - Executive Summary (http://www.epa.gov/dfe/pubs/tools/ctsa/exsum/exsum.htm.), 2010.

[26] Roche, T., The Design for Environmental Compliance Workbench Tool in Product Engineering; Eco-Design, Technologies and Green Energy, D. Talabă and T. Roche, Editors. 2004, Springer: Dordrecht.

[27] Wimmer, W. and Züst, R., ECODESIGN PILOT, ProductInvestigation, Learning- and Optimization-Tool for Sustainable Product Development, 2003, Dordrecht: Kluwer Academics Publishers.

[28] Duflou, J.R. and Dewulf, W., Eco-Impact Anticipation by parametric screening of machine system components: An Introduction to the EcoPaS Methodology, in Product Engineering; Eco-Design, Technologies and Green Energy, D. Talabă and T. Roche, Editors. 2004, Springer: Dordrecht.

[29] Lindahl, M. and Tingström, J., A small textbook on Environment Effect Analysis (EEA), 2000, Kalmar, Sweden: Dept. of Technology, University of Kalmar.

[30] Byggeth, S. and Hochschorner, E., Handling trade-offs in Ecodesign tools for sustainable. Journal of Cleaner Production, 2006. Vol. 14: p. 1420-1430.

[31] Stevels, A., Adventures in EcoDesign of Electronic Products 1993-2007, 2009: VSSD.

[32] Graedel, T.E. and Allenby, B.R., Industrial Ecology. 2nd ed2003, Upper Saddle River: Pearson Education, Inc.

[33] Design for Sustainability Program. Delft University of Technology IdeMat Product Info - IdeMat (http://www.idemat.nl/Product/pi_frame.htm). 2005 [cited 2012 10th of September].

[34] Baumann, H. and Tillman, A.-M., The Hitch Hiker's Guide to LCA - An orientation in life cycle assessment methodology and application, 2004, Lund, Sweden: Studentlitteratur AB.

[35] Brezet, H. and Hemel, C.v., eds. Ecodesign - A Promising Approach to Sustainable Production and Consumption. 1997, Delft University of Technology: Delft, Netherlands.

[36] Wenzel, H., Hauschild, M., and Alting, L., Environmental Assessment of Products - Volume 1: Methodology, tools and case studies in product development, 1997, London: Chapman \& Hall.

[37] Jones, E., Stanton, N., and Harrison, D., Applying structured methods to Eco-innovation. An evaluation of the Product Ideas Tree diagram. Design Studies, 2001. Vol. 22: p. 519542.

[38] Sakao, T., Watanabe, K., and Shimomura, Y. A Method to Support Environmentally Conscious Service Design Using Quality Function Deployment (QFD). in EcoDesign 2003. 2003. Tokyo, Japan.

[39] Luttropp, C. and Lagerstedt, J., EcoDesign and The Ten Golden Rules: generic advice for merging environmental aspects into product development. Journal of Cleaner Production, 2006. Vol. 14: p. 1396-1408.

[40] Chang, H.-T. and Chen, J.L., The conflict-problem-solving CAD software integrating TRIZ into eco-innovation. Advances in Engineering Software, 2004. Vol. 35: p. 553-566. 